University of Nebraska - Lincoln

DigitalCommons@University of Nebraska - Lincoln

Biological Systems Engineering: Papers and

Publications

Biological Systems Engineering

2010

\title{
Microwave-Based Alkali Pretreatment of Switchgrass and Coastal Bermudagrass for Bioethanol Production
}

Deepak R. Keshwani

University of Nebraska-Lincoln, dkeshwani2@unl.edu

Jay J. Cheng

North Carolina State University, jay_cheng@ncsu.edu

Follow this and additional works at: https://digitalcommons.unl.edu/biosysengfacpub

Part of the Biological Engineering Commons

Keshwani, Deepak R. and Cheng, Jay J., "Microwave-Based Alkali Pretreatment of Switchgrass and Coastal Bermudagrass for Bioethanol Production" (2010). Biological Systems Engineering: Papers and Publications. 203.

https://digitalcommons.unl.edu/biosysengfacpub/203

This Article is brought to you for free and open access by the Biological Systems Engineering at DigitalCommons@University of Nebraska - Lincoln. It has been accepted for inclusion in Biological Systems Engineering: Papers and Publications by an authorized administrator of DigitalCommons@University of Nebraska Lincoln. 
Published in Biotechnology Progress 26:3 (2010), pp. 644-652; doi: 10.1002/btpr.371 Copyright (C) 2011 American Institute of Chemical Engineers; published by Wiley-Blackwell. http://www.interscience.wiley.com Used by permission.

Submitted May 21, 2009; revised October 6, 2009; published online December 28, 2009.

\title{
Microwave-Based Alkali Pretreatment of Switchgrass and Coastal Bermudagrass for Bioethanol Production
}

\author{
Deepak R. Keshwani \\ Dept. of Biological Systems Engineering, University of Nebraska-Lincoln, Lincoln, NE 68583 \\ Jay J. Cheng \\ Dept. of Biological and Agricultural Engineering, North Carolina State University, Raleigh, NC 27695 \\ Corresponding author - J. J. Cheng, jay_cheng@ncsu.edu
}

\begin{abstract}
Switchgrass and coastal bermudagrass are promising lignocellulosic feedstocks for bioethanol production. However, pretreatment of lignocelluloses is required to improve production of fermentable sugars from enzymatic hydrolysis. Microwave-based alkali pretreatment of switchgrass and coastal bermudagrass was investigated in this study. Pretreatments were carried out by immersing the biomass in dilute alkali reagents and exposing the slurry to microwave radiation at 250 $\mathrm{W}$ for residence times ranging from 5 to $20 \mathrm{~min}$. Simons' stain method was used to quantify changes in biomass porosity as a result of the pretreatment. Pretreatments were evaluated based on yields of total reducing sugars, glucose, and xylose. An evaluation of different alkalis identified sodium hydroxide as the most effective alkali reagent for microwave-based pretreatment of switchgrass and coastal bermudagrass. $82 \%$ glucose and $63 \%$ xylose yields were achieved for switchgrass and $87 \%$ glucose and 59\% xylose yields were achieved for coastal bermudagrass following enzymatic hydrolysis of biomass pretreated under optimal conditions. Dielectric properties for dilute sodium hydroxide solutions were measured and compared with solid losses, lignin reduction, and reducing sugar levels in hydrolyzates. Results indicate that dielectric loss tangent of alkali solutions is a potential indicator of the severity of microwave-based pretreatments.
\end{abstract}

Keywords: microwave pretreatment, switchgrass, coastal bermudagrass, bioethanol, dielectric properties

\section{Introduction}

Given the steady increase in energy consumption and foreseeable decline in crude oil production, there is considerable interest in establishing renewable energy alternatives. In the United States, ethanol derived from corn is being established as an alternative to gasoline to meet liquid fuel needs. However, limitations on the availability of arable land limit the production of corn-based ethanol and its use as a viable replacement for gasoline consumption. ${ }^{1}$ The increased allocation of corn for ethanol production raises corn prices and could result in reduced exports of animal products due to insufficient availability for feed applications. ${ }^{2}$ Lignocellulosic materials have been identified as promising feedstock for ethanol production. These materials include agricultural residues, newsprint, wood chips, and herbaceous energy crops such as switchgrass and coastal bermudagrass.

Switchgrass (Panicum virgatum L.) is a perennial warmseason grass native to North America. This feedstock shows promise due to high productivity across a wide geographic range, suitability for marginal land quality, low water and nutritional requirements, and positive environmental benefits and was identified as a model energy crop by the United States Department of Energy. ${ }^{3}$ The benefits associated with the perennial nature of switchgrass include less intensive agricultural management practices, reduced energy and agrochemical consumption, and positive effects on soil and wildlife quality. ${ }^{4}$ Biomass yield estimates for switchgrass ranging from 7 to 15 dry tons per acre have been reported in field trials across the southeastern United States. ${ }^{5-7}$

Coastal bermudagrass (Cynodon dactylon L.) is widely grown in the southern United States with dry matter yields of 6-10 tons per acre annually. ${ }^{8}$ This feedstock is grown by many hog farmers in the southeastern United States as part of nutrient management plans to remove nitrogen and phosphorous from swine wastes. ${ }^{9}$ Bermudagrass hay currently has low-commercial value as an animal feed. Hence, utilization of bermudagrass for ethanol would commercially benefit hog farmers. As the agricultural practices for coastal bermudagrass are already in place, it is an attractive feedstock for bioethanol production.

The biochemical conversion of lignocellulosic materials into ethanol involves hydrolysis of cellulose into fermentable sugars and the subsequent fermentation of these sugars into ethanol. The hydrolysis is carried out by carbohydrolases that break down structural carbohydrates into monomeric sugars such as glucose and xylose. Lignocellulosic materials contain cellulose, hemicellulose, and lignin that are 
closely associated in a complex crystalline structure. As a result, the efficiency of the hydrolysis is reduced due to limited accessibility of the enzymes to the substrate. ${ }^{10}$ Hence, pretreatment processes are required to improve the efficiency of enzymatic hydrolysis. The purpose of pretreatment is to remove lignin and/or hemicellulose, reduce crystallinity of cellulose, and increase porosity of the biomass. Several physical, physico-chemical, chemical, and biological pretreatment methods have been studied and comprehensive reviews detailing the mode of action of these pretreatments have been published. ${ }^{1,11}$

For switchgrass, previously examined pretreatments include dilute sulfuric acid pretreatment, ${ }^{12-14}$ lime pretreatment, ${ }^{15}$ ammonia fiber explosion (expansion), ${ }^{16}$ fractionation using ammonia and hydrogen peroxide percolation, ${ }^{17,18}$ and ammonia water-pretreatment. ${ }^{19}$ Recent studies on microwave-based pretreatment ${ }^{20,21}$ and radio frequency-assisted alkali pretreatment ${ }^{22}$ have also been reported. Previous work on bermudagrass includes high-pressure hot water pretreatment, ${ }^{23}$ ammonia fiber explosion, ${ }^{8,24}$ and dilute sulfuric acid pretreatment. ${ }^{9}$

The use of microwave radiation is a promising pretreatment process that utilizes thermal and nonthermal effects generated by microwaves in aqueous environments. The electric and magnetic field components of microwaves apply forces that are rapidly changing direction at the rate of $2.4 \times$ $10^{9}$ times per second. ${ }^{25}$ The vibration of polar molecules and the movement of ions results in the generation of heat and extensive intermolecular collisions. These effects can accelerate chemical, biological, and physical processes. ${ }^{26}$ The interaction of microwaves with any material depends on its dielectric properties: dielectric constant and dielectric loss factor. The dielectric constant is a measure of the ability of a material to store electromagnetic energy and the dielectric loss factor is a measure of the ability of a material to convert electromagnetic energy into heat. ${ }^{27}$ Loss tangent, which is a ratio of dielectric loss factor to the dielectric constant, is a parameter used to describe the overall efficiency of a material to utilize energy from microwave radiation. ${ }^{28}$ Some advantages of microwave heating over conventional heating include reduction of process energy requirements, uniform and selective processing, and ability to start and stop the process instantaneously. ${ }^{29}$ Additionally, since the heat is generated internally via direct interaction between the electromagnetic field and components of the heated material, the heating is volumetric and rapid. ${ }^{30}$

The earliest known study involving microwave pretreatment examined the effect of microwave radiation on rice straw and bagasse immersed in water and reported an improvement in total reducing sugar production by a factor of 1.6 for rice straw and 3.2 for bagasse in comparison to untreated biomass. ${ }^{31}$ Microwave pretreatment of sugarcane bagasse and rice hulls soaked in water followed by lignin extraction was reported to yield $77-84 \%$ of total available reducing sugars. ${ }^{32} \mathrm{~A}$ similar study involving microwave pretreatment of rice straw and sugarcane bagasse followed by lignin extraction reported a yield of $43-55 \%$ of total available reducing sugars. ${ }^{33}$ Microwave-based pretreatment of rice straw soaked in dilute alkali resulted in glucose yield and total carbohydrate conversion of $65 \%$ and $78 \%$, respectively. ${ }^{34}$ A recent study on microwave-based alkali pretreatment of switchgrass reported that sugar yields with microwave heating were higher than yields from conventional heating. ${ }^{20}$ No work related to microwave pretreatment of coastal bermudagrass has been reported and none of these earlier studies have examined dielectric properties relevant to microwave pretreatment of biomass.

The objectives of this study were to evaluate the potential of different alkalis (calcium hydroxide, sodium carbonate, and sodium hydroxide) for microwave-based pretreatment of switchgrass and coastal bermudagrass, identify optimal pretreatment conditions for the most effective alkali reagents, and examine the relationship between dielectric properties of dilute alkali solutions and the effects of the pretreatment process. It is anticipated that measuring the dielectric properties and establishing their effect on the pretreatment process would yield useful information for future studies to model the process, and address scalability and process-design issues.

\section{Materials and Methods}

\section{Biomass}

Switchgrass (oven-dried at $70^{\circ} \mathrm{C}$ ) and coastal bermudagrass (sun-dried) samples were obtained from field sites at North Carolina State University's Central Crops Research Station in Clayton, North Carolina. Switchgrass was harvested in July 2007, and coastal bermudagrass was harvested in June 2007. The feedstock was ground to pass a 2-mm sieve in a Thomas Wiley Laboratory Mill (Model No. 4) and stored in sealed plastic bags at room temperature until use for pretreatment and biomass characterization.

\section{Pretreatment}

Microwave-based pretreatments were carried out in a general purpose laboratory microwave oven (Panasonic Corporation, model NN-S954). The apparatus provided microwave radiation using inverter technology at variable power levels ranging from 125 to $1,250 \mathrm{~W}$. All pretreatments in this study were carried out at a power level of $250 \mathrm{~W}$. For each pretreatment, slurry consisting of $5 \mathrm{~g}$ (dry basis) of the biomass mixed with dilute alkali reagent (solid to liquid ratio of 1:10) was exposed to microwave radiation for the desired pretreatment time. The reaction vessel was a $500-\mathrm{mL}$ glass beaker which was placed at the center of the rotating platform in the microwave. Following pretreatment, the resulting biomass was washed with $200 \mathrm{~mL}$ of deionized water to remove excess chemicals and/or other pretreatment byproducts that might inhibit enzymatic hydrolysis. For pretreatment with calcium hydroxide, low solubility prompted the use of excess $(\sim 1,000 \mathrm{~mL})$ deionized water to remove residual alkali. The contents were filtered under vacuum pressure through a medium porosity (2-5 $\mu \mathrm{m}$ particle retention) quantitative filter paper. Moisture contents of the pretreated biomass were measured after washing and samples were stored in a sealed bag at $4^{\circ} \mathrm{C}$ for enzymatic hydrolysis.

\section{Enzymatic hydrolysis}

Enzymatic hydrolysis of pretreated samples was carried out in 250-mL Erlenmeyer flasks in a controlled environment incubator shaker (New Brunswick, model G-25) set at $55^{\circ} \mathrm{C}$ and $150 \mathrm{rpm}$. One gram (dry basis) of wet pretreated biomass was immersed in $50 \mathrm{mM}$ sodium citrate buffer to maintain a $\mathrm{pH}$ of 4.8. Cellulase (Celluclast 1.5L) from Trichoderma reesei (E.C. 3.2.1.4) was added at an enzyme loading of 
$40 \mathrm{FPU} / \mathrm{g}$ biomass. (FPU = filter paper units). The cellulase activity was supplemented with cellobiase (Novozyme 188) from Aspergillus niger (E.C. 3.2.1.21) at an enzyme loading of $70 \mathrm{CBU} / \mathrm{g}$ biomass. (CBU = cellobiase units). The additional cellobiase was necessary to mitigate cellobiose inhibition of cellulase. ${ }^{35}$ The enzymes were obtained from Novozymes North America, Inc. (Franklinton, NC). Before use, the activities of the enzymes were measured using standard IUPAC procedures. $^{36}$ The measured activities for cellulase and cellobiase were 76.44 FPU/mL and 283.14 CBU/mL, respectively. Sodium azide was added to the hydrolysis mixture at a concentration of $0.3 \% \mathrm{w} / \mathrm{v}$ (weight per volume) to inhibit microbial growth. The hydrolysis was carried out for $72 \mathrm{~h}$ after which the hydrolyzates were centrifuged and the supernatant was stored at $-20^{\circ} \mathrm{C}$ for sugar analysis. The same procedure was used during the optimization of enzyme loading for switchgrass and coastal bermudagrass pretreated under optimum conditions.

\section{Biomass composition and sugar analysis}

Structural carbohydrates and lignin content in the biomass were measured by a two-step acid hydrolysis as per a standard protocol from the National Renewable Energy Laboratory. ${ }^{37}$ Extractives in the biomass were determined by a gravimetric method using a toluene-ethanol mixture. ${ }^{38}$ Total reducing sugars in the hydrolyzates were measured using the dinitrosalicylic acid (DNS) method. ${ }^{39}$ Monomeric sugars in the enzymatic hydrolyzates and composition analysis liquors were measured with an HPLC using a refractive index detector and a Bio-Rad Aminex HPX-87P column tailored for separation of monosaccharides derived from lignocellulosic materials. The column was operated at a flow rate of $0.6 \mathrm{~mL} /$ min at a temperature of $80^{\circ} \mathrm{C}$ using HPLC grade water as the mobile phase. The injection volume was $10 \mu \mathrm{L}$ and the sample-run time was $35 \mathrm{~min}$ with a postrun time of $25 \mathrm{~min}$ between injections.

\section{Measurement of biomass porosity}

The accessibility of the biomass to the hydrolytic enzymes was evaluated by measuring the porosity using Simons' Stain method ${ }^{40,41}$ which is based on the competitive adsorption of two dyes: Direct Orange 15 and Direct Blue 1. The large orange dye molecules can only penetrate large pores in the biomass. They replace the smaller blue dye molecules in these larger pores because of greater affinity for hydroxyl groups of cellulose. ${ }^{42}$ The numbers of both small and large pores are important factors in determining the accessibility of cellulase to the biomass. ${ }^{43}$ The amount of orange and blue dyes adsorbed by the biomass can be used to quantity the relative difference in porosity between biomass samples. ${ }^{44}$ The blue dye has a molecular diameter of $1 \mathrm{~nm}$ which is significantly less than the molecular diameter of the orange dye which ranges from 5 to $7 \mathrm{~nm}{ }^{41,42,44}$

\section{Measurement of dielectric properties}

Dielectric properties of the chemical reagents used to soak the biomass were measured using an open-ended coaxial dielectric probe (Model HP 85070B, Agilent Technologies, Palo Alto, CA) connected to a network analyzer (Model HP 8753C, Agilent Technologies) based on a previously reported procedure. ${ }^{27}$ The solutions were placed in a cylindrical vessel fitted with a dielectric probe and temperature probe and
Table 1. Composition (wt \% on a dry basis) of untreated switchgrass and coastal bermudagrass used in this study (reported values are means of three replicates with standard deviations in parenthesis)

\begin{tabular}{lcc}
\hline Component & Switchgrass & Bermudagrass \\
\hline Glucan & $31.3(1.4)$ & $25.0(1.2)$ \\
Xylan & $18.4(0.83)$ & $16.3(0.76)$ \\
Arabinan & $1.92(0.42)$ & $1.99(0.31)$ \\
Galactan & $1.69(0.25)$ & $1.43(0.13)$ \\
Acid insoluble lignin & $18.2(1.5)$ & $15.4(1.1)$ \\
Acid soluble lignin* & $4.32(0.34)$ & $3.96(0.19)$ \\
Extractives & $4.87(0.94)$ & $4.17(1.2)$ \\
Ash & $3.96(0.82)$ & $6.60(1.4)$ \\
\hline
\end{tabular}

* Acid soluble lignin was measured at $205 \mathrm{~nm}$ and calculated using an absorptivity value of $110 \mathrm{~L} /(\mathrm{g} \mathrm{cm})$.

sealed using a tri-clamp fitting. The vessel was heated to desired temperatures using an oil bath (Model RTE111, Neslan Instruments Inc., Newington, NH). The network analyzer was programmed to record dielectric properties for frequencies ranging from 200 to 3,000 $\mathrm{MHz}$ when a desired temperature was reached. Dielectric properties were measured for temperatures ranging from $20^{\circ} \mathrm{C}$ to $120^{\circ} \mathrm{C}$ at intervals of $20^{\circ} \mathrm{C}$.

\section{Overview of experimental scheme}

The effectiveness of sodium carbonate $\left(\mathrm{Na}_{2} \mathrm{CO}_{3}\right)$, calcium hydroxide $\left(\mathrm{Ca}(\mathrm{OH})_{2}\right)$, and sodium hydroxide $(\mathrm{NaOH})$ as alkali reagents for microwave-based pretreatment of switchgrass and coastal bermudagrass was determined. Biomass samples were immersed in $2 \% \mathrm{w} / \mathrm{v}$ alkali solutions and exposed to microwave radiation for $10 \mathrm{~min}$. The pretreated samples were enzymatically hydrolyzed and total reducing sugars were measured. The improvement in hydrolysis in comparison to untreated biomass was used to identify the best alkali reagent(s) for each feedstock. Porosity of pretreated switchgrass samples was measured to explain the differences in sugar yields for pretreatment with different alkalis.

After the identification of optimum alkali reagent(s) for the pretreatment of switchgrass and coastal bermudagrass, a factorial experiment was designed in each case to study the effects of concentration and pretreatment time and any potential interactions. The experimental design consisted of three levels of alkali concentration $(1 \%, 2 \%$, and $3 \% \mathrm{w} / \mathrm{v})$ and four levels of pretreatment time $(5,10,15$, and $20 \mathrm{~min})$. Comparisons between pretreatments were based on yields of total reducing sugars, glucose and xylose after accounting for solid losses during pretreatment.

\section{Statistical analysis}

All experiments in this study were conducted in triplicate and statistical analysis was done using SAS 9.1.3 (SAS Institute Inc., Cary, NC). Error bars shown in all figures are based on standard deviation values. Comparisons between treatment means were carried out using the Tukey adjustment under PROG GLM functionality. The Tukey adjustment enables comparison of multiple treatments while maintaining the probability of Type I error $(\alpha)$ at 0.05 . 


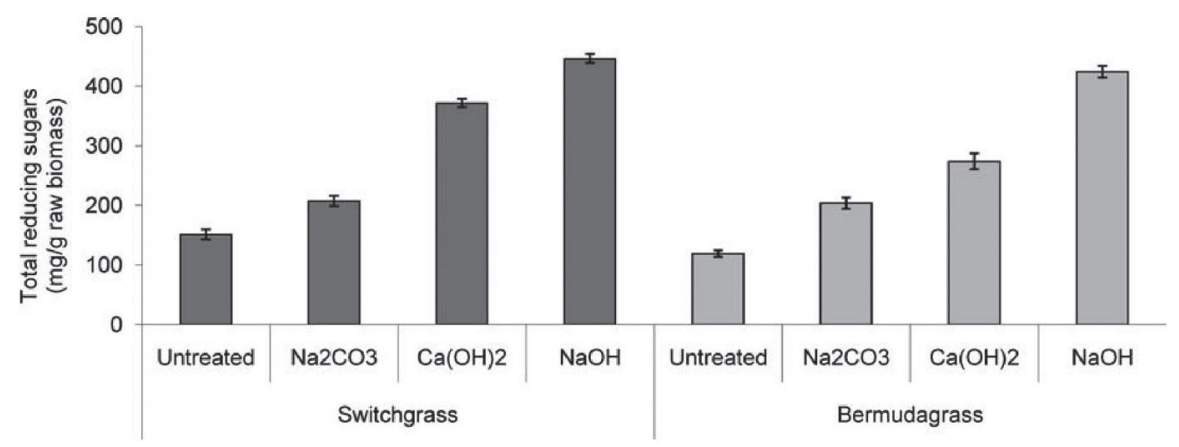

Figure 1. Total reducing sugar production from enzymatic hydrolysis of untreated biomass and washed microwave-pretreated biomass using different alkali reagents.

\section{Results and Discussion}

\section{Biomass characterization}

Chemical composition of the feedstocks used in this study is shown in Table 1. Although the amounts of minor carbohydrates (arabinan and galactan) were similar for both feedstocks, switchgrass had significantly higher glucan, xylan, and lignin. Using anhydro corrections ( 0.88 for six carbon sugars and 0.9 for five carbon sugars), the maximum amounts of glucose and xylose from switchgrass theoretically available for conversion into ethanol are $355 \mathrm{mg} / \mathrm{g}$ biomass and $204 \mathrm{mg} / \mathrm{g}$ biomass, respectively. For bermudagrass, these amounts are $284 \mathrm{mg} / \mathrm{g}$ biomass for glucose and $181 \mathrm{mg} / \mathrm{g}$ biomass for xylose. These theoretically available amounts of sugars were the basis for the \%sugar yields reported in this study.

\section{Evaluation of different alkali reagents}

Three different alkali reagents were evaluated $\left(\mathrm{Na}_{2} \mathrm{CO}_{3}\right.$, $\mathrm{Ca}(\mathrm{OH})_{2}$, and $\left.\mathrm{NaOH}\right)$ for the pretreatment of switchgrass and coastal bermudagrass using $2 \% \mathrm{w} / \mathrm{v}$ alkali concentration and 10 min pretreatment time with a solid to liquid ratio of 1:10. Reducing sugar yields (based on raw biomass) from enzymatic hydrolysis of pretreated biomass was compared with untreated biomass (control) (Figure 1). For switchgrass, reducing sugar yields for microwave pretreatment with $\mathrm{Na}_{2} \mathrm{CO}_{3}, \mathrm{Ca}(\mathrm{OH})_{2}$, and $\mathrm{NaOH}$ were 207,372 , and $446 \mathrm{mg} / \mathrm{g}$. These yields are significantly and substantially higher than the yield from untreated switchgrass $(151 \mathrm{mg} / \mathrm{g})$. For coastal bermudagrass, reducing sugar yields for microwave pretreatment with $\mathrm{Na}_{2} \mathrm{CO}_{3}, \mathrm{Ca}(\mathrm{OH})_{2}$, and $\mathrm{NaOH}$ were 204, 274, and $424 \mathrm{mg} / \mathrm{g}$, respectively. These yields are significantly and substantially higher than the yield from untreated bermudagrass (119 mg/g). For both feedstocks, pretreatment with $\mathrm{NaOH}$ resulted in significantly higher reducing sugar yields over pretreatment with $\mathrm{Na}_{2} \mathrm{CO}_{3}$ and $\mathrm{Ca}(\mathrm{OH})_{2}$. Therefore, $\mathrm{NaOH}$ was chosen for further study to optimize the concentration and time for both switchgrass and bermudagrass.

To explain the differences in the performance of $\mathrm{Na}_{2} \mathrm{CO}_{3}$, $\mathrm{Ca}(\mathrm{OH})_{2}$, and $\mathrm{NaOH}$ as an alkali reagent for microwave pretreatment, the porosity of pretreated switchgrass was quantified using the Simons' Stain method. The amounts of the smaller blue dye and the larger orange dye adsorbed by the biomass indicate the extent to which the accessibility to cellulase improved because of the pretreatment. A recent study reported a correction coefficient $\left(r^{2}\right)$ of 0.95 between adsorption of Simons' stain dye and hydrolysis yields. ${ }^{45}$

Figure $2 \mathrm{a}$ shows the adsorption of the blue dye by pretreated switchgrass. The extent of absorption was significantly
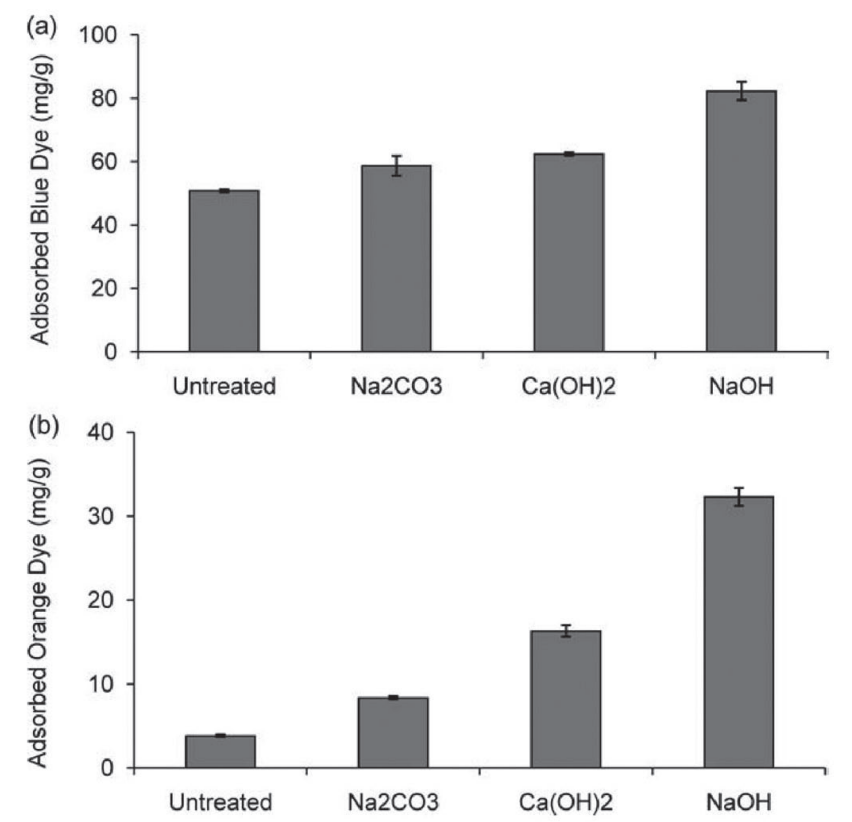

Figure 2. Amount of dye adsorbed by untreated and microwavepretreated switchgrass using different alkali reagents (a) blue dye (molecular diameter of $1 \mathrm{~nm}$ ) and (b) orange dye (molecular diameter of 5-7 $\mathrm{nm}$ ).

higher for biomass treated with all alkalis in comparison to untreated switchgrass. Dye adsorption was statistically similar for biomass pretreated with $\mathrm{Na}_{2} \mathrm{CO}_{3}$ and $\mathrm{Ca}(\mathrm{OH})_{2}(59$ and $62 \mathrm{mg} / \mathrm{g}$, respectively). The highest adsorption was observed for biomass pretreated with $\mathrm{NaOH}(82 \mathrm{mg} / \mathrm{g})$. Figure $2 \mathrm{~b}$ shows the adsorption of the orange dye by pretreated switchgrass. Like the blue dye, the extent of absorption of the orange dye was significantly higher for biomass treated with alkalis than for untreated switchgrass. However, biomass pretreated with $\mathrm{Na}_{2} \mathrm{CO}_{3}$ adsorbed substantially lower orange dye than biomass pretreated with $\mathrm{Ca}(\mathrm{OH})_{2}(8.3$ and $16 \mathrm{mg} / \mathrm{g}$, respectively). The adsorption of orange dye was the highest for $\mathrm{NaOH}(32 \mathrm{mg} / \mathrm{g})$.

From Figure 2, it is observed that the relative differences in dye adsorption between different alkali pretreatments are more pronounced for the orange dye. This is not surprising since one of the purposes of pretreatment is the disruption of the biomass structure to increase porosity. A stronger alkali like $\mathrm{NaOH}$ will result in a more severe pretreatment causing more disruption to the biomass structure and creating a higher number of large pores. The molecular diameter of the orange dye (5-7 nm) is comparable to reported dimensions of the catalytic core of endoglucanase from Trichoderma reesei 

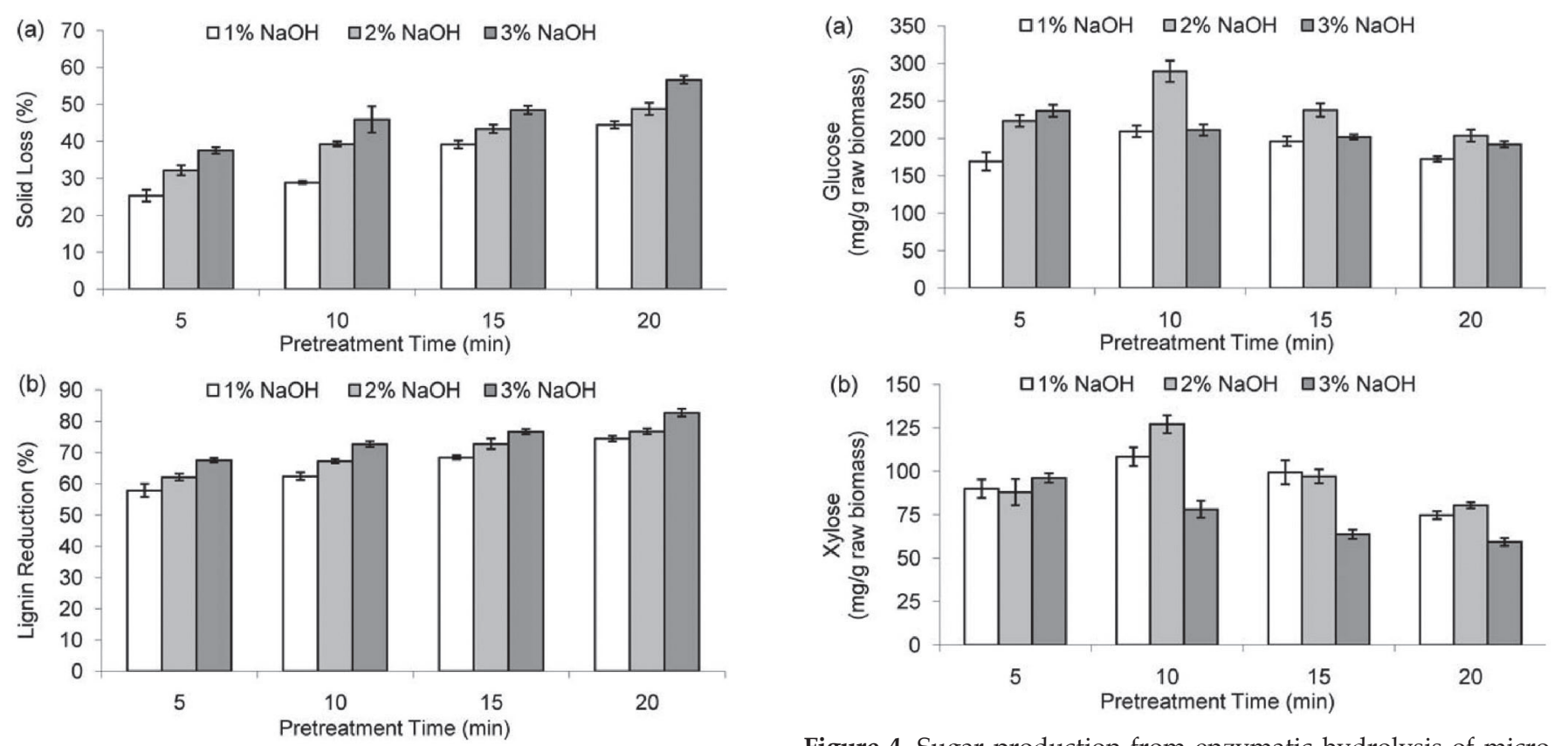

Figure 3. Solid loss and lignin reduction during microwave pretreatment of switchgrass using $\mathrm{NaOH}$.

$(4 \times 5 \times 6 \mathrm{~nm}) .{ }^{41}$ Since the orange dye is adsorbed into the larger pores, it is reasonable to expect the amount adsorbed to more accurately reflect the accessibility of the biomass to the enzyme.

\section{Microwave pretreatment of switchgrass using $\mathrm{NaOH}$}

Figure 3a shows the solid losses for pretreatment of switchgrass using $\mathrm{NaOH}$ at the conditions studied in the experimental design. Solid losses ranged from $25 \%$ for pretreatment with $1 \% \mathrm{NaOH}$ for $5 \mathrm{~min}$ to $57 \%$ for pretreatment with $3 \% \mathrm{NaOH}$ for $20 \mathrm{~min}$. The overall effects of concentration and time were significant. An increase in the severity of the pretreatment by increasing $\mathrm{NaOH}$ concentration or pretreatment time resulted in significantly higher solid losses. Statistical analysis also included some noteworthy interaction effects that elucidate the effect of concentration and time in determining pretreatment severity. Changing pretreatment conditions by increasing one factor while simultaneously decreasing the other has no effect on solid losses during pretreatment. For example, solid loss at $2 \% \mathrm{NaOH}$ and 5 min was statistically similar to solid loss at $1 \% \mathrm{NaOH}$ and $10 \mathrm{~min}$. Such similarity was also observed for the following pairs of pretreatment conditions: 1\%, 15 min and 2\%, 10 min; $1 \%, 20 \mathrm{~min}$ and $2 \%, 15 \mathrm{~min} ; 2 \%, 10 \mathrm{~min}$ and $3 \%, 5 \mathrm{~min} ; 2 \%$, $15 \mathrm{~min}$ and 3\%, $10 \mathrm{~min}$; and 2\%, $20 \mathrm{~min}$ and $3 \% 15 \mathrm{~min}$.

Figure $3 \mathrm{~b}$ shows the lignin reduction caused by the pretreatment of switchgrass using $\mathrm{NaOH}$ at the conditions studied in the experimental design. Lignin reduction ranged from $58 \%$ for pretreatment with $1 \% \mathrm{NaOH}$ for $5 \mathrm{~min}$ to $83 \%$ for pretreatment with $3 \% \mathrm{NaOH}$ for $20 \mathrm{~min}$. The overall trends were similar to those observed for solid loss. The effects of both alkali concentration and pretreatment time were significant. Higher concentration and longer pretreatments resulted in higher lignin reduction. The interaction effects were similar to those observed for solid loss. This further supports the contention that both alkali concentration and pretreatment time influence the severity of the pretreatment process.

Figure 4. Sugar production from enzymatic hydrolysis of microwave-pretreated switchgrass using $\mathrm{NaOH}$ (a) glucose and (b) xylose.

Figure 4a shows the glucose yield from switchgrass at different pretreatment conditions of the experimental design. The highest yield $(289 \mathrm{mg} / \mathrm{g})$ was obtained for pretreatment with $2 \% \mathrm{NaOH}$ for $10 \mathrm{~min}$. For $1 \%$ and $2 \% \mathrm{NaOH}$, peak yields were obtained at pretreatment time of $10 \mathrm{~min}$. However, for $3 \% \mathrm{NaOH}$, glucose yield continually decreased with increasing pretreatment time due to higher solid loss. The effect of alkali concentration on glucose yields also varied with pretreatment time. For a pretreatment time of $5 \mathrm{~min}$, glucose yield significantly increased with increasing alkali concentration. At all other pretreatment times (10 min and longer), glucose yield peaked at $2 \% \mathrm{NaOH}$ with significantly lower yields at $1 \%$ and $3 \% \mathrm{NaOH}$.

Figure $4 \mathrm{~b}$ shows the xylose yield from switchgrass at different pretreatment conditions of the experimental design. The highest yield $(127 \mathrm{mg} / \mathrm{g})$ was obtained for pretreatment with $2 \% \mathrm{NaOH}$ for $10 \mathrm{~min}$. The overall effect of pretreatment time on xylose yields was similar to that observed for glucose yields. For $1 \%$ and $2 \% \mathrm{NaOH}$, peak xylose yields were obtained at $10 \mathrm{~min}$. For 3\% $\mathrm{NaOH}$, xylose also continually decreased with as pretreatment time was increased. However, this decrease in xylose yield at $3 \% \mathrm{NaOH}$ was more pronounced than the decrease in glucose yield at $3 \% \mathrm{NaOH}$. The effect of alkali concentration on xylose yields also varied with pretreatment time. For a pretreatment time of $5 \mathrm{~min}$, alkali concentration was not a significant factor. At longer pretreatment times (10 min and more), xylose yields were highest at $2 \% \mathrm{NaOH}$. One exception to note is at $15 \mathrm{~min}$, where xylose yields at $1 \%$ and $2 \%$ were not significantly different.

\section{Microwave pretreatment of coastal bermudagrass using $\mathrm{NaOH}$}

Figure 5a shows the solid losses for pretreatment of coastal bermudagrass using $\mathrm{NaOH}$ at the conditions studied in the experimental design. Solid losses ranged from $32 \%$ for pretreatment with $1 \% \mathrm{NaOH}$ for 5 min to $59 \%$ for pretreatment with $3 \% \mathrm{NaOH}$ for $20 \mathrm{~min}$. The overall effects of concentra- 

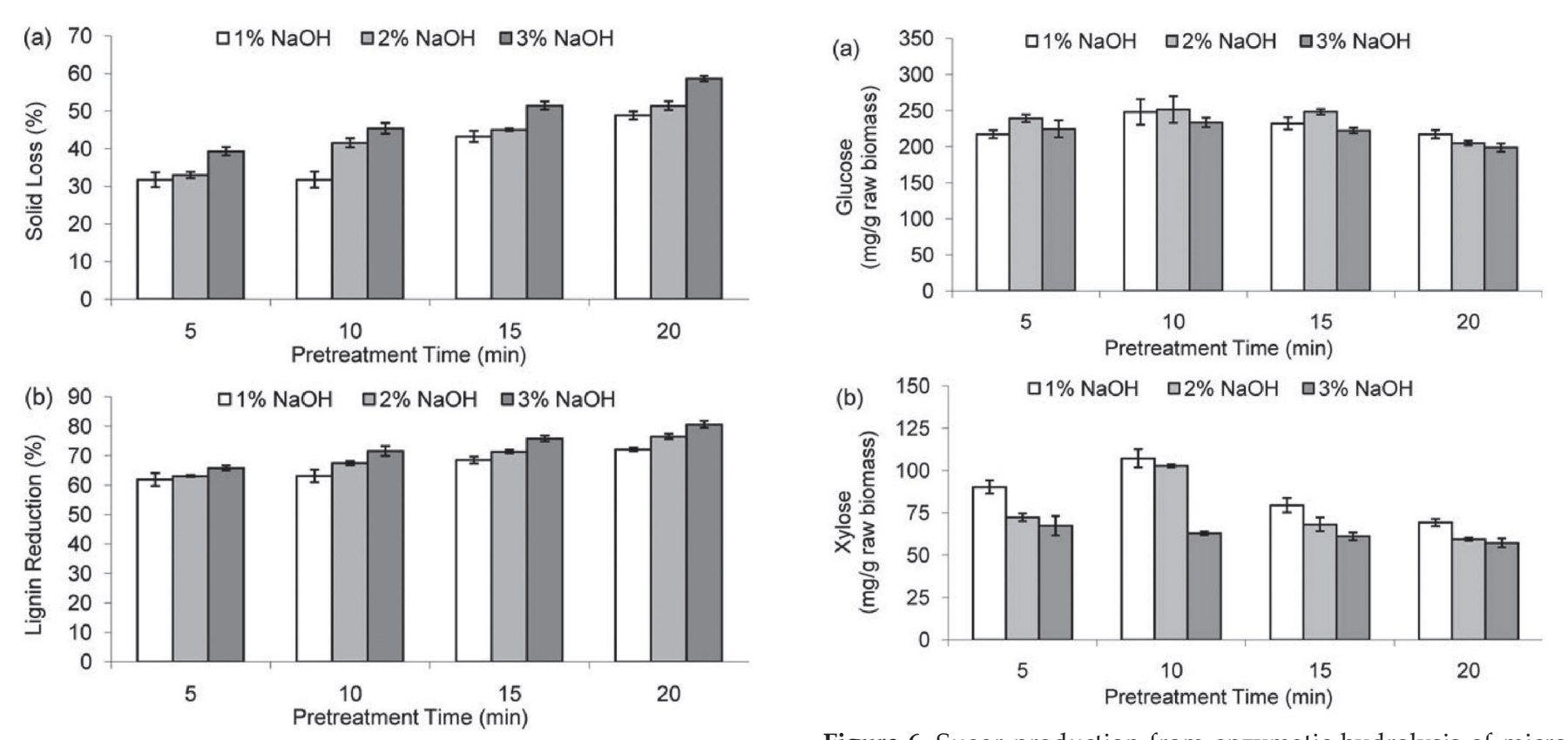

Figure 5. Solid loss and lignin reduction during microwave pretreatment of coastal bermudagrass using $\mathrm{NaOH}$.

tion and time were significant and trends were similar to those observed for switchgrass. An increase in the severity of the pretreatment by increasing $\mathrm{NaOH}$ concentration or pretreatment time generally resulted in significantly higher solid losses. An exception occurs for a pretreatment time of 5 min, where the difference between solid losses at $1 \%$ and $2 \%$ $\mathrm{NaOH}$ was not significant.

Figure $5 b$ shows the lignin reduction caused by the pretreatment of coastal bermudagrass using $\mathrm{NaOH}$ at the conditions studied in the experimental design. Lignin reduction ranged from $62 \%$ for pretreatment with $1 \% \mathrm{NaOH}$ for $5 \mathrm{~min}$ to $81 \%$ for pretreatment with $3 \% \mathrm{NaOH}$ for $20 \mathrm{~min}$. The overall trends were similar to those observed for lignin reduction of switchgrass. Higher concentration and longer pretreatments resulted in higher lignin reduction. An exception occurs for a pretreatment time of $5 \mathrm{~min}$, where the difference between lignin reduction at $1 \%$ and $2 \% \mathrm{NaOH}$ was not significant. The interaction effects were similar to those observed for lignin reduction of switchgrass.

Figure 6a shows the glucose yield from coastal bermudagrass at different pretreatment conditions of the experimental design. The highest yield (252 mg/g) was obtained for pretreatment with $2 \% \mathrm{NaOH}$ for 10 min but was statistically similar to the glucose yield at $1 \% \mathrm{NaOH}$ and $10 \mathrm{~min}(248 \mathrm{mg} / \mathrm{g})$. An additional experiment at $0.5 \% \mathrm{NaOH}$ and 10 min resulted in significantly lower glucose yield (198 mg/g). Sugar yields increased as the pretreatment time was extended from 5 to 10 min and then decreased at longer pretreatment times. The effect of alkali concentration on glucose yields also varied with pretreatment time. At pretreatment times of $5 \mathrm{~min}$ and 10 min, glucose yield was not significantly influenced by alkali concentration. The concentration effect becomes significant at pretreatment times of 15 and $20 \mathrm{~min}$.

Figure $6 \mathrm{~b}$ shows the xylose yield from coastal bermudagrass at different pretreatment conditions of the experimental design. The highest yield $(107 \mathrm{mg} / \mathrm{g}$ ) was obtained for pretreatment with $1 \% \mathrm{NaOH}$ for $10 \mathrm{~min}$. An additional experiment at $0.5 \% \mathrm{NaOH}$ and 10 min resulted in significantly lower xylose yield $(86.1 \mathrm{mg} / \mathrm{g})$. The overall trend for the effect of

Figure 6. Sugar production from enzymatic hydrolysis of microwave-pretreated coastal bermudagrass using $\mathrm{NaOH}$ (a) glucose and (b) xylose.

time was similar to the trend observed for xylose production from switchgrass. For $1 \%$ and $2 \% \mathrm{NaOH}$ sugars, peak xylose yields were obtained at $10 \mathrm{~min}$. For $3 \% \mathrm{NaOH}$, xylose also continually decreased as pretreatment time was increased. The effect of alkali concentration on xylose yields did not vary with pretreatment time. In general, a decrease in alkali concentration resulted in reduced xylose yields. A notable exception is at a pretreatment time of 10 min where xylose yields at $1 \%$ and $2 \% \mathrm{NaOH}$ were not significantly different.

\section{Differences between switchgrass and coastal bermudagrass}

During the study, some differences between switchgrass and coastal bermudagrass were observed. The most important difference observed was the $\mathrm{NaOH}$ requirements for optimum pretreatment conditions. Switchgrass required 2\% $\mathrm{NaOH}$ and coastal bermudagrass required $1 \% \mathrm{NaOH}$. This could be explained by the lower amount of lignin present in bermudagrass in comparison to switchgrass (19\% vs. $22 \%$ ).

Another difference noted between switchgrass and coastal bermudagrass was the overall sugar yields. For switchgrass, glucose yields increased from 30 to $82 \%$ and $x y-$ lose yields increased from 9 to $63 \%$ after optimal pretreatment. For coastal bermudagrass, glucose yields increased from 34 to $87 \%$ and xylose yields increased from 7 to $60 \%$ after optimal pretreatment. Although the xylose yields for both feedstocks are similar, the glucose yields are higher for bermudagrass (raw and pretreated). To explain this, the porosity of the untreated and optimally pretreated feedstock was quantified using the Simons' stain method. Figures 7a,b show the amount of blue (smaller) dye and orange (larger) dye adsorbed by untreated switchgrass and coastal bermudagrass. Untreated coastal bermudagrass adsorbed $\sim 30 \%$ more blue dye and 50\% more orange dye in comparison to untreated switchgrass. This indicates that untreated coastal bermudagrass is more porous than untreated switchgrass and is therefore more susceptible to enzymatic hydrolysis. A similar result was observed when the Simons' stain method was used on optimally pretreated biomass (Figures 7c,d). 

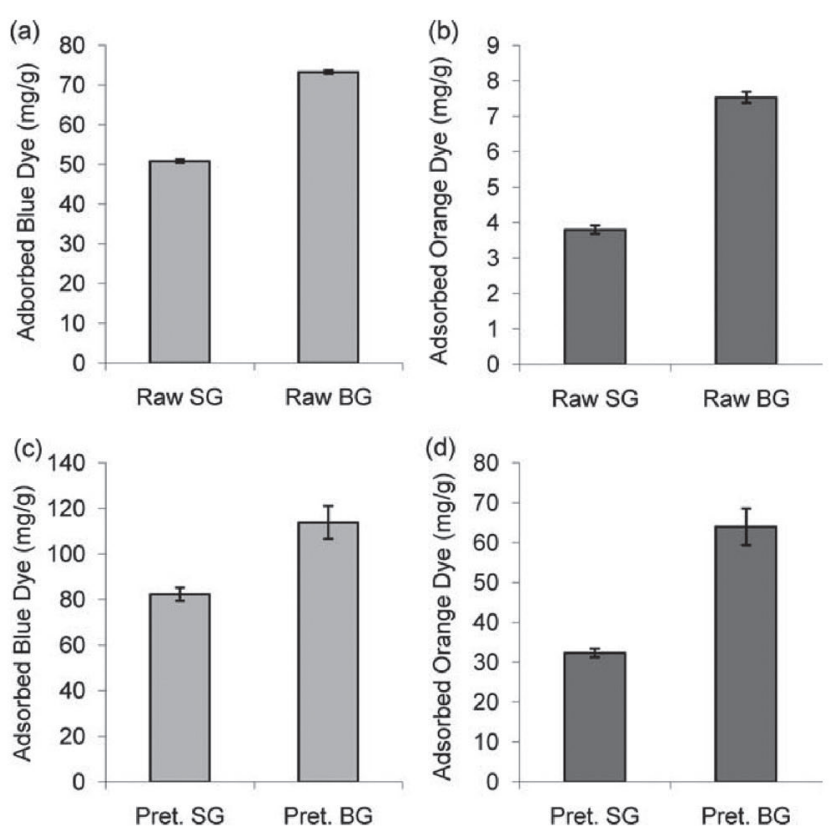

Figure 7. Amount of dye adsorbed by untreated (raw) and microwave-pretreated (under optimal conditions) biomass (a) blue dye adsorbed by raw switchgrass (Raw SG) and raw coastal bermudagrass (Raw BG), (b) orange dye adsorbed by Raw SG Raw BG, (c) blue dye adsorbed by pretreated switchgrass (Pret. SG) and pretreated coastal bermudagrass (Pret. BG), and (d) orange dye adsorbed by Pret. SG and Pret. BG.

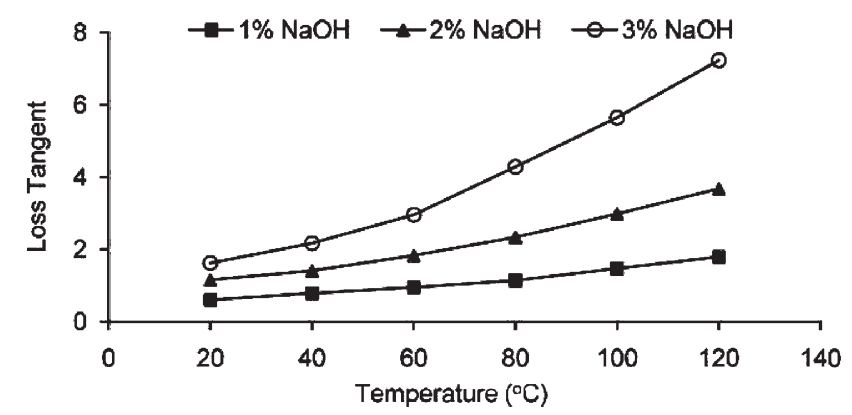

Figure 8. Dielectric loss tangents of dilute $\mathrm{NaOH}$ solutions at different temperatures.

Pretreated coastal bermudagrass adsorbed $28 \%$ more blue dye and $50 \%$ more orange dye in comparison to pretreated switchgrass. This indicates that pretreated coastal bermudagrass is more porous than pretreated switchgrass and is therefore more susceptible to enzymatic hydrolysis.

\section{Dielectric properties of $\mathrm{NaOH}$}

Dielectric properties of dilute $\mathrm{NaOH}$ solutions were measured for temperatures ranging from $20^{\circ} \mathrm{C}$ to $120^{\circ} \mathrm{C}$ at microwave frequencies from 200 to 3,000 MHz. The data set at $2,450 \mathrm{MHz}$ was isolated. The dielectric loss tangents for $1 \%$, $2 \%$, and $3 \% \mathrm{w} / \mathrm{v} \mathrm{NaOH}$ solutions are shown in Figure 8 . The loss tangent increases in value with increasing concentration and the relative differences are more significant at higher temperatures. Therefore, solutions of higher alkali concentration are more effective in absorbing microwave energy and converting the stored energy into heat. Since the conduction of ions is a major factor for thermal and nonthermal effects in microwave processes, a system with a higher con-
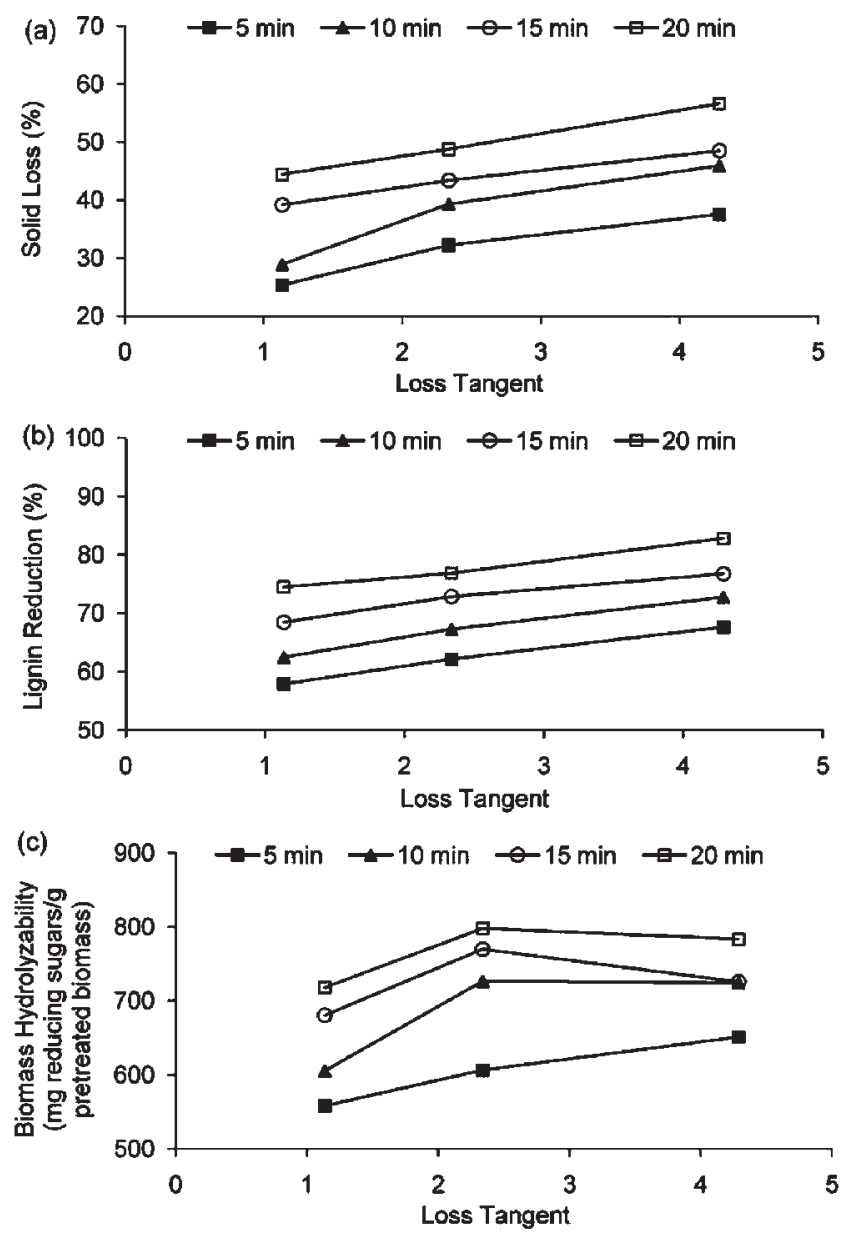

Figure 9. Relationship between dielectric loss tangent and (a) solid loss, (b) lignin reduction, and (c) biomass hydrolyzability at different pretreatment times.

centration of $\mathrm{NaOH}$ will exhibit more ionic conduction in response to microwave pretreatment.

During the pretreatment experiments, it was observed that the average bulk temperature of the slurry during microwave-based alkali pretreatment at $250 \mathrm{~W}$ was between $80^{\circ} \mathrm{C}$ and $85^{\circ} \mathrm{C}$. Dielectric loss tangents at $80^{\circ} \mathrm{C}$ corresponding to the appropriate $\mathrm{NaOH}$ concentrations were compared with solid losses (Figure 9a), lignin reduction (Figure 9b), and biomass hydrolyzability (Figure 9c) from microwave pretreatment of switchgrass using $\mathrm{NaOH}$. Solid losses and lignin reduction increase as loss tangent increases at all pretreatment times. However, biomass hydrolyzability (expressed as mg of reducing sugars per $\mathrm{g}$ of pretreated biomass) does not exhibit this relationship with the loss tangent. This indicates that dielectric properties of alkali solutions are a reasonable indicator of pretreatment severity. However, they are not indicative of biomass hydrolyzability, which is likely to be significantly influenced by the presence of residual lignin and crystallinity index of cellulose in the pretreated biomass.

\section{Comparison with other studies}

For switchgrass, optimal pretreatment with $2 \% \mathrm{NaOH}$ for 10 min resulted in the highest sugar yields with $82 \%$ for glucose and $63 \%$ for xylose. Yields for microwave-based pretreatment of switchgrass using $\mathrm{NaOH}$ compare well with other studies on pretreatment of switchgrass (Table 2). AFEX 
Table 2. Sugar yields from different studies on pretreatment of switchgrass and coastal bermudagrass

\begin{tabular}{|c|c|c|c|c|}
\hline Biomass & Pretreatment & $\%$ glucose yield & $\%$ xylose yield & Reference number \\
\hline \multirow[t]{6}{*}{ Switchgrass } & Lime $\left(\mathrm{Ca}(\mathrm{OH})_{2}\right)$ & 58 & 58 & 15 \\
\hline & Ammonia & $45-56$ & $25-31$ & 19 \\
\hline & AFEX & 93 & $>90$ & 16 \\
\hline & RF heating- $\mathrm{NaOH}$ & 85 & 84 & 22 \\
\hline & Microwave-NaOH & $78-88$ & $87-96$ & 20 \\
\hline & Microwave-NaOH & 82 & 63 & This study \\
\hline Bermudagrass & Microwave-NaOH & 87 & 59 & This study \\
\hline
\end{tabular}

pretreatment of switchgrass reported a higher glucose yield $(93 \%)$ but ammonia requirements noted in the study were high (1 kg of ammonia per $\mathrm{kg}$ of dry biomass). ${ }^{16}$ Glucose yields are comparable to studies on $\mathrm{NaOH}$ pretreatment of switchgrass using microwave radiation and radio frequency heating, but xylose yields were lower since both these studies accounted for the xylose solubilized into the pretreatment liquor when determining overall sugar yields. ${ }^{20,22}$

For coastal bermudagrass, optimal pretreatment with $1 \%$ $\mathrm{NaOH}$ for 10 min increased glucose yields from 34 to $87 \%$ and increased xylose yields from 7 to $59 \%$ compared with untreated bermudagrass. Glucose yields compare favorably with results reported from dilute acid pretreatment ${ }^{9}$ and AFEX pretreatment ${ }^{8}$ (data shown in Table 2). However, the dilute acid pretreatment study ${ }^{9}$ reported $81 \%$ xylose yield in the prehydrolyzate, which is not surprising since the primary mode of action of dilute acid pretreatment is solubilization of hemicelluloses into the prehydrolyzate. ${ }^{1,11}$ In the case of alkaline pretreatment, the mode of action is the removal of lignin, which improves the enzymatic hydrolysis of the polysaccharides that remain. ${ }^{11}$

\section{Conclusions}

Microwave-based pretreatment of switchgrass and coastal bermudagrass was investigated to improve sugar yields from enzymatic hydrolysis. A comparison of different alkalis determined that pretreatment with $\mathrm{NaOH}$ gave the highest total reducing sugar yields for microwave-based pretreatment of both feedstocks. Significant differences in the porosity of the biomass pretreated with different alkalis were observed using the Simons' stain method. For switchgrass, optimal pretreatment with $2 \% \mathrm{NaOH}$ for 10 min resulted in yields of $82 \%$ for glucose and $63 \%$ for xylose. For coastal bermudagrass, optimal pretreatment with $1 \% \mathrm{NaOH}$ for 10 min resulted in yields of $87 \%$ for glucose and $59 \%$ for xylose. Based on NREL's theoretical ethanol yield calculator, yields were calculated for both feedstocks. For pretreated switchgrass, theoretical ethanol yields were 44 gallons per dry ton (based on fermentation of only glucose) and 64 gallons per dry ton (based on fermentation of both glucose and xylose). For pretreated coastal bermudagrass, the corresponding theoretical ethanol yields were 38 (glucose) and 55 (glucose and xylose) gallons per dry ton.

Dielectric properties of dilute $\mathrm{NaOH}$ solutions were measured and compared with solid losses, lignin reduction, and biomass hydrolyzability. It was noted that dielectric loss tangents increase with increasing $\mathrm{NaOH}$ concentration. Furthermore, it was determined that loss tangents are a reasonable indicator of pretreatment severity in terms of solid loss and lignin reduction, but do not accurately reflect the sugar production potential of pretreated biomass.
This study has shown the feasibility of microwave-based alkali pretreatment of lignocellulosic materials to improve yields of fermentable sugars available for ethanol production. However, the experiments were conducted in a laboratory-scale batch microwave system. Currently, most industrial applications involving microwave-based processing use continuous systems. Therefore, the next logical step is to verify the feasibility of this pretreatment method using laboratory scale continuous microwave systems. This will enable the identification of appropriate process parameters that will be useful in the scale-up of microwave-based pretreatment. In addition, future studies should also address scalability considerations such as capital cost, energy consumption, and water requirements for the process.

Acknowledgments - The authors thank the Golden LEAF Foundation of North Carolina and the North Carolina Biotechnology Center for funding this study, Dr. Joseph Burns from the Crop Science Department of North Carolina State University for providing the biomass, Dr. K. P. Sandeep from the Food Science Department of North Carolina State University for access to analytical equipment, and Novozymes North America (Franklinton, North Carolina, USA) for providing the enzymes used in this study.

\section{Literature Cited}

1. Sun Y, Cheng J. Hydrolysis of lignocellulosic materials for ethanol production: A review. Bioresour Technol. 2002 83:1-11.

2. Elobeid A, Tokgoz S, Hart C. The ethanol outlook for Brazil and the United States and implications for livestock. Int Sugar J. 2007 109:174-177.

3. McLaughlin SB. New switchgrass biofuels research program for the southeast. Proceedings of Technical Meeting, Dearborn, MI. Nov. 2-5, 1992. Ann Aut Techn. 1993:111-115.

4. Dunn CP, Stearns F, Guntenspergen GR, Sharpe DM. Ecological benefits of the conservation reserve program. Conserv Biol. 1993 7:132-139.

5. Parrish DJ, Fike JH. The biology and agronomy of switchgrass for biofuels. Crit Rev Plant Sci. 2005 24:423-459.

6. Sanderson MA, Reed RL, McLaughlin SB, Wullschleger SD, Conger BV, Parrish DJ, Wolf DD, Taliaferro C, Hopkins AA, Ocumpaugh WR, Hussey MA, Read JC, Tischler CR. Switchgrass as a sustainable bioenergy crop. Bioresour Technol. 1996 56: 83-93.

7. Thomason WE, Raun WR, Johnson GV, et al. Switchgrass response to harvest frequency and time and rate of applied nitrogen. J Plant Nutr. 2004 27:1199-1226.

8. Holtzapple MT, Ripley EP, Nikolaou M. Saccharification, fermentation, and protein recovery from low-temperature 
afex-treated coastal bermudagrass. Biotechnol Bioeng. 1994 44:1122- 1131.

9. Sun Y, Cheng JJ. Dilute acid pretreatment of rye straw and bermudagrass for ethanol production. Bioresour Technol. 2005 96: 1599-1606.

10. McMillan JD. Pretreatment of lignocellulosic biomass. In: Enzymatic Conversion of Biomass for Fuels Production, Himmel ME, Baker JO, Overend RP., Editors. Vol. 566. 1994:292- 324.

11. Mosier N, Wyman C, Dale B, et al. Features of promising technologies for pretreatment of lignocellulosic biomass. Bioresour Technol. 2005 96:673-686.

12. Chung YC, Bakalinsky A, Penner MH. Enzymatic saccharification and fermentation of xylose-optimized dilute acid-treated lignocellulosics. Appl Biochem Biotechnol. 2005 121:947-961.

13. Dien BS, Jung HJG, Vogel KP, et al. Chemical composition and response to dilute-acid pretreatment and enzymatic saccharification of alfalfa, reed canarygrass, and switchgrass. Biomass Bioenergy. 2006 30:880-891.

14. Fenske JJ, Esteghlalian A, Mckinnis J, Hashimoto AG, Penner $\mathrm{MH}$. Optimization of dilute-acid pretreatment of switchgrass. Abstr Pap Am Chem Soc. 1994 207:70-BIOT.

15. Chang VS, Burr B, Holtzapple MT. Lime pretreatment of switchgrass. Appl Biochem Biotechnol. 1997 63:3-19.

16. Alizadeh H, Teymouri F, Gilbert TI, Dale BE. Pretreatment of switchgrass by ammonia fiber explosion (AFEX). Appl Biochem Biotechnol. 2005 121:1133-1141.

17. Iyer PV, Wu ZW, Kim SB, Lee YY. Ammonia recycled percolation process for pretreatment of herbaceous biomass. Appl Biochem Biotechnol. 1996 57:121-132.

18. Kim SB, Lee YY. Fractionation of herbaceous biomass by ammonia-hydrogen peroxide percolation treatment. Appl Biochem Biotechnol. 1996 57:147-156.

19. Kurakake M, Kisaka W, Ouchi K, Komaki T. Pretreatment with ammonia water for enzymatic hydrolysis of corn husk, bagasse, and switchgrass. Appl Biochem Biotechnol. 2001 90:251-259.

20. Hu ZH, Wen ZY. Enhancing enzymatic digestibility of switchgrass by microwave-assisted alkali pretreatment. Biochem Eng J. 2008 38:369-378.

21. Keshwani DR, Cheng JJ, Burns JC, Li L, Chiang V. Microwave pretreatment of switchgrass to enhance enzymatic hydrolysis. 2007 ASABE Annual Meeting, Minneapolis, MN. Jun. 17-20, 2007. Paper number 077127.

22. Hu ZH, Wang YF, Wen ZY. Alkali $(\mathrm{NaOH})$ pretreatment of switchgrass by radio frequency-based dielectric heating. Appl Biochem Biotechnol. 2008 148:71-81.

23. Brandon SK, Eiteman MA, Patel K, et al. Hydrolysis of Tifton 85 bermudagrass in a pressurized batch hot water reactor. $J$ Chem Technol Biotechnol. 2008 83:505-512.

24. Delarosa LB, Reshamwala S, Latimer VM, Shawky BT, Dale $\mathrm{BE}$, Stuart ED. Integrated production of ethanol fuel and protein from coastal bermudagrass. Appl Biochem Biotechnol. 1994 45: 483-497.

25. Galema SA. Microwave chemistry. Chem Soc Rev. 1997 26:233-238.

26. Sridar V. Microwave radiation as a catalyst for chemical reactions. Curr Sci. 1998 74:446-450.

27. Kumar P, Coronel P, Simunovic J, Truong VD, Sandeep KP. Measurement of dielectric properties of pumpable food materials under static and continuous flow conditions. J Food Sci. 2007 72:E177-E183.
28. Nelson SO, Datta CJ. Dielectric properties of food materials and electric field interactions. In: Datta $\mathrm{AK}$, Anantheswaran RC, editors. Handbook of Microwave Technology for Food Applications. New York: Marcel Dekker Inc. 2001:69-107.

29. Datta AK. Fundamentals of heat and moisture transport for microwaveable food product and process development. In: Datta AK, Anantheswaran RC, editors. Handbook of Microwave Technology for Food Applications. New York: Marcel Dekker Inc. 2001:115-166.

30. de la Hoz A, Diaz-Ortiz A, Moreno A. Microwaves in organic synthesis. Thermal and non-thermal effects. Chem Soc Rev. 2005 34:164-178.

31. Ooshima H, Aso K, Harano Y, Yamamoto T. Microwave treatment of cellulosic materials for their enzymatic-hydrolysis. Biotechnol Lett. 1984 6:289-294.

32. Azuma JI, Tanaka F, Koshijima T. Enhancement of enzymatic susceptibility of lignocellulosic wastes by microwave irradiation. J Ferment Technol. 1984 62:377-384.

33. Kitchaiya P, Intanakul P, Krairiksh M. Enhancement of enzymatic hydrolysis of lignocellulosic wastes by microwave pretreatment under atmospheric-pressure. J Wood Chem Technol. 2003 23:217-225.

34. Zhu SD, Wu YX, Yu ZN, Liao JT, Zhang Y. Pretreatment by microwave. Process Biochem. 2005 40:3082-3086.

35. Ryu DDY, Mandels M. Cellulases - biosynthesis and applications. Enzyme Microb Technol. 1980 2:91-102.

36. Ghose TK. Measurement of cellulase activities. Pure Appl Chem. 1987 59:257-268.

37. Sluiter A, Hames B, Ruiz R, Scarlata C, Sluiter J, Templeton D. Determination of structural carbohydrates and lignin in biomass. Laboratory analytical procedure, NREL/TP-510-42618. 2007 online at http://www.nrel.gov/biomass/analytical procedures.html ; accessed October 10, 2007.

38. Han J, Rowell J. Chemical composition of agro-based fibers. In: Rowell R, Young AR, Rowell J, editors. Paper and Composites from Agro-Based Resources. New York: CRC Lewis Publishers 1997:81-134.

39. Miller GL. Use of dinitrosalicylic acid reagent for determination of reducing sugar. Anal Chem. 1959 31:426-428.

40. Simons FL. A stain for use in the microscopy of beaten fibers. Tappi J. 1950 33:312-314.

41. Esteghlalian AR, Bilodeau M, Mansfield SD, Saddler JN. Do enzymatic hydrolyzability and Simons' stain reflect the changes in the accessibility of lignocellulosic substrates to cellulase enzymes? Biotechnol Prog. 2001 17:1049-1054.

42. Yu XC, Minor JL, Atalla RH. Mechanism of action of Simons' stain. Tappi J. 1995 78:175-180.

43. Tanaka M, Ikesaka M, Matsuno R, Converse AO. Effect of pore-size in substrate and diffusion of enzyme on hydrolysis of cellulosic materials with cellulases. Biotechnol Bioeng. 1988 32:698-706.

44. Yu XC, Atalla RH. A staining technique for evaluating the pore structure variations of microcrystalline cellulose powders. Powder Technol. 1998 98:135-138.

45. Chandra R, Ewanick S, Hsieh C, Saddler JN. The characterization of pretreated lignocellulosic substrates prior to enzymatic hydrolysis, part 1: A modified Simons' staining technique. Biotechnol Prog. 2008 24:1178-1185. 